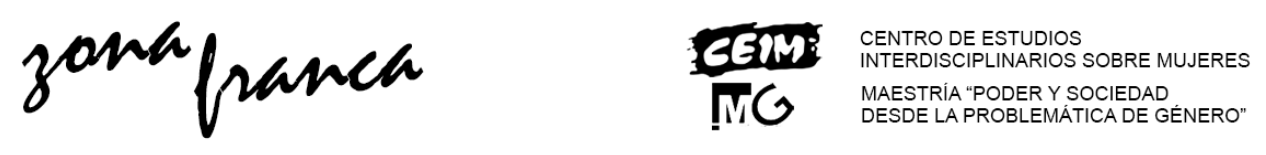

\title{
Lectoras y escritoras en El grillo de papel(1959-60) y El escarabajo de oro (1961-9)
}

Tania Diz *

\section{Resumen}

Este artículo se propone analizar elementos de las revistas El grillo de papel y en El escarabajo de oro con el objetivo de reconstruir el imaginario socio sexual que se desprende de ellas. Se parte de la hipótesis de que en los textos que no son ficcionales, prevalecen ideas conservadoras del binarismo sexual con diferentes gradaciones de misoginia y homofobia. En primer lugar, se analiza la figura de la lectora circunscripta a la novela amorosa y al mercado; en segundo lugar se analiza la imagen de la alteridad que surge en la figura de Victoria Ocampo y en tercer lugar, la aparición del feminismo en las voces de Simone de Beauvoir y de María Rosa Oliver. Finalmente, se concluye que el androcentrismo imperante deja como resultado una mirada que se resiste a pensar identidades fuera del sistema sexo-género y esto trae consecuencias negativas tanto en el modo en que las escritoras permanecen en el campo literario como respecto de la emergencia del feminismo y de la disidencia sexual.

Palabras clave: Feminismo- Escritoras- Revistas culturales

\section{Reader and writer woman in El grillo de papel (1959-60) and EI escarabajo de oro (1961-9)}

\begin{abstract}
This research approach will seek to review El grillo de papel and El escarabajo de orowith the objective of know sexual imaginary of them. In the non fictional texts, the ideas defend the gender system even misogyny and homophobia. First, I study the woman reader linked to love novel; second I study the representation of Victoria Ocampo and, by last, feminism in Simone de

*Universidad de Buenos Aires. CONICET. Contacto: taniadiz@gmail.com

Diz, Tania. "Lectoras y escritoras en El grillo de papel (1959-60) y El escarabajo de oro (1961-9)" en Zona Franca. Revista del Centro de estudios Interdisciplinario sobre las Mujeres, y de la Maestría poder y sociedad desde la problemática de Género, N²6, 2018 pp.80-106. ISSN, 2545-6504 Recibido: 10 de mayo, 2018; Aceptado: 27 de agosto 2018
\end{abstract}

Revista Zona Franca- Centro de estudios interdisciplinario sobre las mujeres (CEIM)- Maestría poder y sociedad desde la problemática de género (MG), Rosario, Argentina. ISSN, 2545-6504 http://zonafranca.unr.edu.ar/index.php/ZonaFrancal Numero 26 (2018).

Página 80 
Beauvoir and María Rosa Oliver. Finally, androcentrism covers the changes in sexual identities and this affects woman writer and feminist movement.

Keywords: Feminism- women's writing- cultural magazines

\section{Escritoras encarnadas e imaginadas en los sesenta}

Abelardo Castillo dirigió tres revistas literarias ${ }^{1}$ que abarcan casi treinta años y tuvieron un protagonismo más que relevante en el campo cultural de los sesenta y setenta en Argentina. La primera fue El grillo de papel, conformada por seis números que salen a lo largo de los años 1959-60; luego se editó El escarabajo de oro de 1961 a 1974 y por último El ornitorrinco de 1977 a 1986. Con sus diferencias, tienen rasgos comunes que hacen que se las considere sucesivas. Las tres revistas están marcadas por la influencia del pensamiento de Sartre (Saítta 2015; Calabrese 2006), por una intención explícitamente polemista y de intervención en el campo intelectual; y por considerar como esferas separadas lo puramente estético en la literatura respecto del compromiso político del escritor (esta era la polémica más importante entre los escritores cercanos a la izquierda). (Ferrero 2007; Blanco 2006) Justamente, debido a este punto es que se diferencian y discuten, sobre todo Abelardo Castillo y Arnoldo Libermann, con otras dos revistas asociadas a la ortodoxia del Partido Comunista Argentino, me refiero a Gaceta Literaria y a Cuadernos de cultura. (Grande Cobián 2006) Otro aspecto común es el tono fuertemente condenatorio o celebratorio en las lecturas que hacen de la literatura contemporánea, así como también el despliegue de un

1 Las citas de las revistas El grillo de papel; El escarabajo de oro y El ornitorrinco están especifiadas según lo requerido. Cabe aclarar que se ha trabajado con las ediciones digitalizadas en el sitio www.ahira.com.ar

Revista Zona Franca- Centro de estudios interdisciplinario sobre las mujeres (CEIM)- Maestría poder y sociedad desde la problemática de género (MG), Rosario, Argentina. ISSN, 2545-6504 http://zonafranca.unr.edu.ar/index.php/ZonaFranca| Numero 26 (2018). 
sólido aparato crítico desde el que valoran o critican lo que se está editando.

En este artículo propongo analizar en El grillo de papel y en El escarabajo de

oro las ideas que subyacen respecto de lo femenino y del feminismo, partiendo del supuesto de que predomina el pensamiento androcéntrico que en ciertos casos llega a la misoginia y a la homofobia. Es decir que se considera lo masculino y heterosexual como los modos de la identidad hegemónica, ubicando en un lugar subalterno a la feminidad y despreciando a la homosexualidad. Esta es la razón por la que las mujeres que colaboran en la revista tienden a mimetizarse con la hegemonía masculina y a rechazar una marcación de género, percibida como agraviante.

Por eso es que en general desde la revista se rechaza de plano cualquier posición tildada de feminista y/o vinculada a la homosexualidad. Por ejemplo, a pesar de que se manifiestan en contra de la censura, son indiferentes a la cuestión homosexual que se visibiliza en el "Caso Correas". ${ }^{2}$ Estas posiciones que formaban parte de lo común en la época, no suponen la exclusión de las

${ }^{2}$ El caso se refiere al secuestro de la revista Centro nro 14, en 1959, en la que se publica el cuento "La narración de la historia" de Carlos Correas. La razón de la censura era la supuesta inmoralidad del relato debido al tratamiento de la temática homosexual. Además del secuestro de la revista, se judicializó a su director, Jorge Laforgue, y al autor. En la editorial del número 15 de El escarabajo de oro, Castillo se detiene en qué es la literatura para su grupo (la obra debe ser bella y testimonial, dice), discutiendo sobre todo con David Viñas y Oscar Masotta, quienes propusieron al caso Correas como ejemplo del escritor comprometido, lo que para Castillo es "inadmisible" según su propia declaración en el número 15 de El escarabajo de oro, p.4. En la editorial del número siguiente, Castillo vuelve contra el cuento de Correas y el artículo de Masotta ("Seis intentos frustrados de escribir sobre Roberto Arlt") ya que, según él, ambos atacan a Arlt. La polémica cita notas de Hoy en la cultura en las que Viñas sobre todo, critica a Castillo; en síntesis, es la lucha por el lugar que cada uno de ellos ocupa en el campo intelectual, cuestión en la que no ahondaremos. Sólo para ejemplificar las posiciones homofóbicas que traslucía la revista y la falta de comprensión de la dimensión política del tema, cito las palabras de Castillo: "Si bien no juzgamos ética o moralmente a los homosexuales, tampoco (¿por qué habríamos de tenérsela?) les tenemos especial simpatía. Como escribió Arlt: si son enfermos, que vayan al médico." (Castillo 1963: p.4)

Revista Zona Franca- Centro de estudios interdisciplinario sobre las mujeres (CEIM)- Maestría poder y sociedad desde la problemática de género (MG), Rosario, Argentina. ISSN, 2545-6504 http://zonafranca.unr.edu.ar/index.php/ZonaFranca| Numero 26 (2018).

Página 82 
mujeres del campo intelectual, sino más bien, una inclusión en tanto iguales que disimulan u ocultan sus singularidades. En este sentido, no es casual que la imagen de la lectora casi no exista sino que, o bien se la incluye en la del lector, o bien se la estereotipa de un modo que genera el rechazo de las mujeres que forman parte de este grupo, cuestión que veremos más adelante. Las escritoras circulan bastante por la revista sean como colaboradoras, como autoras o como reseñadas y se recortan dos perfiles: la señora burguesa que hace mala literatura con éxito en el mercado y la joven independiente que busca mimetizarse con los hombres para ocultar su diferencia.

Algunas de las escritoras y obras femeninas que aparecen en la revista son: las escritoras consagradas entre las que está una de las más queridas por el grupo, Beatriz Guido, quien celebra la existencia de la revista a la que lee como señal venturosa de la nueva generación. En El escarabajo de oro, se reseña El incendio y las vísperas, y Guido es considerada, junto con Sara Gallardo y David Viñas, como referente de la novela argentina. También se menciona, en un lugar secundario, a otras como Griselda Gambaro o Silvina Ocampo - en el cuarto número de El grillo de papel, Castillo firma una reseña demoledora sobre La furia, sin ir más lejos-. Además, se publican cuentos o poemas de Adelaida Gigli, María Mombrú, Diana Castelar, Susana Tasca, Pirí Lugones, Ana María Ponce, Leila Varsi; y se reseñan a escritoras - best seller como es el caso de Silvia Bullrich y el 
de Marta Lynch; junto con otras de menor presencia en el campo cultural. ${ }^{3} \mathrm{P}$ or último, quien se recorta como la escritora joven de la generación es Liliana Heker, quien oficia de secretaria de redacción, colaboradora, hasta llegar a ser vicedirectora de la revista. Además, publica relatos propios y se comentan sus primeros libros de cuentos. Como es sabido, Heker se ha destacado principalmente por los ensayos que publicaba en las revistas y que generaban intensos debates al interior del campo intelectual. En uno de ellos, "Las hermanas de Shakespeare" (Heker 1967), se detiene en la cuestión de la literatura femenina, adoptando un posicionamiento cómplice del discurso hegemónico y de explícito rechazo hacia el feminismo. Básicamente, afirma que la mujer actual está en igualdad de condiciones que el varón, que el feminismo es un desvío burgués o es el fruto del resentimiento de ciertas mujeres; argumentos que formaban parte del modo de pensar en esos años. En verdad, lo que subyace es que Heker se distancia así del modelo que Bullrich representa: escritoras exitosas en el mercado pero consideradas como exponentes de la peor literatura.

En líneas generales, la revista no le da importancia a las cuestiones de género, sean vinculadas al feminismo o a los movimientos de identidad homosexual. Podría justificarse esta hipótesis por el hecho de que el feminismo

\footnotetext{
${ }^{3}$ Tafur, Alicia (reseña) ““Un momento muy largo” de Silvina Bullrich”, El escarabajo de oro, nro. 4, nov.- dic 1961, p. 34.

Vazquez Santamaría, Javier (reseña) "Y una sobre la burguesía. Los burgueses" de Silvina Bullrich" El escarabajo de oro, nro 28, abril 65, p.11-13.

Heker, Liliana (reseña) “"La señora Ordoñez” de Marta Lynch”, El escarabajo de oro, nro. 38, feb.marzo 1969, p. 14-15.

Heker, Liliana (reseña) “"Nada que ver con otra historia” de Griselda Gambaro”, El escarabajo de oro, nro.46, junio 73 , p. 26-7.

Tafur, Alicia (reseña) "“'La cárcel y los hierros” de Alicia Jurado” El escarabajo de oro, nro. 3, sept oct 61, p. 30.

Revista Zona Franca- Centro de estudios interdisciplinario sobre las mujeres (CEIM)- Maestría poder y sociedad desde la problemática de género (MG), Rosario, Argentina. ISSN, 2545-6504 http://zonafranca.unr.edu.ar/index.php/ZonaFranca| Numero 26 (2018). 
como movimiento en Argentina se hace visible en la década siguiente, pero los colaboradores tienen contacto con personalidades del extranjero que ya están planteando estas cuestiones, es decir que más que desconocerlas, las dejan de lado. Respecto de los movimientos de identidad homosexual sucede algo similar pero esto se complejiza con el tema del secuestro de la revista Centro debido a la publicación de "La narración de la historia" de Carlos Correas. En consecuencia, predomina la reproducción irreflexiva del discurso hegemónico sobre la sexualidad, más allá de que también puedan leerse algunos desvíos o fisuras que ya iremos analizando. Cabe aclarar que lo dicho sobre la mujer y la sexualidad no es aplicable en absoluto a la ficción que se publica en la misma revista, más bien lo contrario, como puede leerse en "El marica" y "La madre de Ernesto" de Abelardo Castillo o en "Una hermosa familia" de Beatriz Guido. Pero en este artículo, no nos referiremos a ellos.

\section{La lectora y el amor}

El modelo de lector de las revistas fundadas por Castillo tiene características muy precisas: es un lector dispuesto a recorrerla casi por completo para leer un artículo, interesado por la realidad política nacional e internacional, comprometido con las ideas de izquierda, atento a las novedades literarias y a las discusiones de los intelectuales del momento. Si recorremos la sección de las reseñas, es decir, el lugar en donde los colaboradores son lectores, asistimos al ensayo de un ejercicio crítico exhaustivo, con análisis que acusan recibo del estructuralismo, del marxismo, del existencialismo y, aunque no sea predominante, del psicoanálisis. 
Los nombres femeninos se suceden en ambos roles - reseñista y reseñada- ${ }^{4}$ y no hay, mayormente, marcas de género en las reseñas, más allá de alguna frase en la que se califica despectivamente como femenina la manera de escribir de alguna escritora. De todos modos, no predomina el sexismo como a inicios de siglo $\mathrm{XX}$, época en la que era usual la valoración de lo positivo y negativo en términos de virilidad o feminidad.

La mujer que lee, como tal, aparece sólo dos veces, en secciones marginales y bastante estereotipadamente: hallamos una lectora en una historieta en el año 1959, en El grillo de papel, y otra en una nota en la sección "Bicherías", en El escarabajo de oro en 1961. En ambas versiones, la lectora es la consumidora de la cultura de masas. El primer caso es el de una historieta firmada por Villarreal y que se titula "El grillo y la lucha de clases". A pesar del título, más que la lucha de clases, lo que aparece es una divertida tipología de lectores a través de seis escenas en la que cinco hombres y una mujer están leyendo la revista y la modifican substancialmente. Es sencillo identificar en estos cuadros, los estereotipos que se reproducen. En la serie masculina está el erudito, el cura, el lector común - que se aburre con tantas palabras y la sacude-, el que por leerla es acusado de comunista y el estadista o funcionario que recorta el dibujo del grillo y tira el resto. Un sólo cuadro está dedicado a una mujer y ella hace de la revista, una novela de amor: es la joven soñadora que con la revista en

\footnotetext{
${ }^{4}$ Las firmas femeninas son: Liliana Heker, Rosa Axel, Armida Ralesky, Alicia Tafur, Lelia Varsi, Sylvia Iparraguirre, Alicia Tafur, Aurelia de Chailor, entre otras. Las escritoras reseñadas son: Margarite Durás, Simone de Beauvoir, Beatriz Guido, Silvina Bullrich, Jorgelina Loubet, Griselda Gambaro, Alicia Jurado, Silvina Ocampo, entre otras.

Revista Zona Franca- Centro de estudios interdisciplinario sobre las mujeres (CEIM)- Maestría poder y sociedad desde la problemática de género (MG), Rosario, Argentina. ISSN, 2545-6504 http://zonafranca.unr.edu.ar/index.php/ZonaFranca| Numero 26 (2018). 
sus manos, imagina que el título es La grillonovela de papel y que ya en la primera página hallará "Un cuento de amor", mientras el grillito característico de la revista, está rodeado de corazones.

El siguiente caso es una colaboración de Norberto Firpo con el título "Como encarar una novela de amor". En tono de sorna, el periodista comienza dirigiéndose a "aquellos señores que quieran iniciarse en el arte de la novela rosa" e inmediatamente describe a la lectora:

"Se trata de interesar más o menos literariamente a lectoras que oscilarán entre los 13 y los 25 años, edad en que la mujer tiene tal concepto del casamiento que cree que todo lo que no está escrito en relación íntima con él no vale la pena ser leído." (Firpo 1961: 14)

Y más adelante afirma:

"El casamiento será por supuesto, el broche de oro de la obra. No olvidar que el noventa por ciento de las lectoras empiezan a leer el libro por atrás y que lo abandonan si de antemano saben que todo no acabará bien. Por eso sufren tanto con el radioteatro." (Firpo 1961: 14)

Luego continúa caracterizando a los personajes- básicamente tres: la pareja y alguno/a malvado que difame a la protagonista-; los capítulos - cinco dedicados a la biografía y caracterización de los protagonistas y otro cinco para las peripecias-; y, más adelante, recomienda un escenario bucólico para el final. El artículo culmina con algunas sugerencias extra, por ejemplo, agregar una enfermedad como la tuberculosis o alguna ceguera momentánea; o bien sumar alguna acción de rescate por parte del muchacho hacia la chica. $Y$ dice en el 
último párrafo:

"El autor no debe olvidar que las novelas de amor son formativas del carácter de la mujer, por lo tanto no deben estar inspiradas en la vida. En la historia los hombres serán buenos o malos, pero no las dos cosas al mismo tiempo. Y todo terminará como la lectora aspire a que termine la novela de su propia vida." (Firpo 1961: 14)

La lectora ha sido extensamente representada - y estudiada- tanto en las publicaciones periódicas como en la ficción narrativa. $\mathrm{Y}$ en este sentido, es pertinente traer a colación la hipótesis de Nora Catelli quien afirma que en el siglo XIX se celebraba la lectura femenina y a inicios del siglo XX, comienza una etapa de satanización de la misma hasta dudar acerca del valor individual y social de la lectura. (Catelli 2001, Batticuore 2005) Entrado el siglo XX, aparece otra figura de lectora que es la de periódicos y de magazines, ya no tan celebrada. Influye el crecimiento del mercado y el dispositivo de la domesticidad que normativizaba los modos de ser y las aspiraciones femeninas. Además, se recorta un único tema: el amor. Así, el estereotipo de la lectora romántica va tomando forma con rasgos mayormente conservadores y va a ir aggiornandose a los soportes nuevos que surgen a lo largo del tiempo: novelas semanales, radioteatro, fotonovela, películas, etc. Es decir que se impone un modo de la imaginación melodramática, vigente en los años sesenta, vinculado a la cultura de masas y que además fusiona ésta a lo femenino. Huyseen reflexionando acerca de la división entre cultura de masas y alta cultura, ha pensado bastante este vínculo en los países centrales pero creo es útil también para pensarlo en nuestro caso. Si bien en los sesenta la situación de 
la mujer en la cultura ha cambiado, aún, en Argentina, funcionan estos vestigios sexistas por el que se distingue entre arte elevado y cultura popular; a la vez que se devalúa en femenino a esta última.

De todos modos, en ambos ejemplos, la acción de la lectora supone cierto movimiento en el que vale la pena detenerse. En la historieta, la mirada de la lectora tiñe de amor y romanticismo a la revista y el efecto es el humor. Así, el "leer femenino" transforma lo que sea en novelas de amor; tal como observó Catelli en Madame Bovary. La novela de Flaubert condensó la imagen de la mujer moderna dominada por los peligros de la lectura y Catelli complejizó aún más esta idea, al decir que el problema de Bovary no era que leyera novelas románticas sino que transformara en éstas, todo lo que leía. Justamente es la operación que realiza la lectora en la historieta, traducirla en una novela de amor que, incluso, hablará de ella misma. En el artículo de Firpo, la lectora es una déspota que obliga al autor a escribir del modo en que ella quiere leer. Es más, es significativo que Firpo explicite un aspecto central del género: estas novelas son prescriptivas de la subjetividad femenina. $Y$ sabe, también, que las lectoras padecen de bovarysmo en su sentido más clásico, ya que confunden la ficción con su propia vida. Lo ilusorio se reduce al casamiento con el hombre amado, en tanto episodio que obnubila o deja en segundo plano cualquier otro aspecto relativo a las expectativas de la mujer. Si bien esta está lejos de ser una versión anacrónica de la mujer, es más es un modelo de lectora que tenía un consumo cultural importante en la época y, entonces, había un mercado que funcionaba en relación a ella; sí se puede decir que es un modelo acicateado por otros ligados a la 
libertad sexual, a la decisión de la mujer sobre la concepción y a la elección de otros valores, como la carrera profesional, en desmedro del matrimonio. (Cosse 2010) Es más, sin salir del universo de la revista, esta lectora se contrapone a las colaboradoras de la misma, y me parece que esta es la razón por la que algunas escritoras prefieran reproducir el androcentrismo y, entonces, tiendan a afirmar y descalificar lo considerado "femenino", que se reduce a este estereotipo. Por último, la lectora de novelas de amor como una tirana que obliga al autor a escribir lo que ella quiere leer oculta otro elemento clave: el mercado. Es decir, el autor debe aceptar las reglas para tener un éxito que se expresa en las ventas.

\section{Victoria Ocampo: afectos, maternidad y burguesía}

En las páginas de la revista, Victoria Ocampo funciona como referente de la cultura, aún en las antípodas ideológicas de la troupe Castillo. Una de las veces en que aparece es en una editorial de El grillo de papel que tiene por referente la polémica en el país ante el secuestro de Adolf Eichmann. La editorial se titula La ley de las vísceras, está firmada por Abelardo Castillo y Arnoldo Liberman y se centra en la denuncia de los autores ante el proteccionismo de Argentina respecto de Eichmann. Los autores se detienen en relatos escabrosos sobre lo que puede comprenderse bajo el lexema "horror nazi". En este contexto, para acentuar la indignación que cruzaría las fronteras ideológicas, dicen: "Victoria Ocampo, la Victoria Ocampo que respetamos, lo dijo mejor que nadie: sólo se puede reaccionar con el estómago. Por eso, no sólo entregaríamos a Eichmann al pueblo judío: se lo arrojaríamos." (2). Así, los autores toman como propia la frase adjudicada a Ocampo que suspende la razón, las diferencias ideológicas y 
encuentra un punto en común: el humanitarismo. Entonces, la frase, explícitamente a-política, es la que, sin ir más lejos, inspira el título del artículo. Pero los autores dan un paso más al decir, seguidamente: "Nuestro derecho, nuestra obligación, es imaginar lo que fue aquello, imaginarlo bien, hasta que sea insoportable. Y después vomitar. Entonces entenderemos mejor qué quieren los hombres cuando hablan de revolución." Así, la abyección, según Kristevaes el sentimiento que penetra el cuerpo y se expresa en forma de vómito para separarse violentamente de lo que se rechaza. Este es el punto común a los tres; pero Ocampo queda allí, en el cuerpo, y ellos, en cambio, continúan el camino hacia la comprensión y la razón. Se podría decir que sólo por las diferencias ideológicas es obvio que Ocampo ya no puede estar en ese lugar, sin embargo, hay algo más: el modo en que se incluye un aspecto infrecuente en el pensamiento de izquierda de la época: el cuerpo y la afectividad. Es decir que la feminidad de Ocampo es lo que habilita el ingreso de las emociones como el lugar desde donde se conoce el horror nazi. Si al golpe en el estómago, le sucede lo abyecto que es de las más violentas rebeliones del sujeto ante aquello que lo amenaza; la posición femenina es la que registra y resalta la sensación de extrañeza frente a lo humano. Sutilmente emerge el binarismo sexual desde el que se revela la jerarquía entre emoción y razón, donde la primera queda ligada a lo femenino y subsumida a la razón; que quedaría en manos masculinas.

¿Recodarían Castillo y Libermann que Ocampo (la persona) asistió a los juicios de Nuremberg en 1946? ¿Sabrían que un amante y amigo suyo, Drieu de la Rochelle, se alió al nazismo y dejó constancia escrita de su odio a los judíos? 
¿Sabrían que ella ayudó a una poeta judía a huir de los nazis? Probablemente. Pero en verdad no se refieren a ella, ni a sus intervenciones respecto del nazismo, sino que su nombre reúne tres facetas de un modelo de subjetividad alterno al lector de la revista: lo emocional, lo femenino y lo burgués. Como sus editores lo dicen hasta el cansancio, es una publicación anticapitalista y de izquierda; en este sentido es antiburguesa; y por eso, la última de las facetas es la más tematizada. En cambio, es menos evidente la construcción de un otro afectivo y femenino, que, de todos modos, emerge. Karin Littau, en su libro sobre la lectura, afirma que la literatura ha tenido tradicionalmente tres grandes objetivos: causar placer, instruir y conmover. Pero el papel de los afectos ha sido considerado menor por parte de la teoría literaria; y creo que esta afirmación podría trasladarse al ideario de la revista, tanto cuando hacen crítica literaria como cuando opinan sobre cuestiones políticas. En este sentido, no es casual que sea la figura de Ocampo la que les permita introducir en la editorial, la afectividad.

En otra ocasión, la revista publica un reportaje a César Tiempo, con el que tienen ciertos lazos en común ya que perteneció al grupo de Boedo, que en los años veinte ya levantaban las banderas de la literatura comprometida con las causas sociales. En este sentido, puede decirse que este reportaje, así como algunas reediciones que hacen de Raúl González Tuñón, les son útiles para posicionarse en la tradición letrada. Tiempo, por un lado, se niega a contar nuevamente la historia de Clara Beter y, por otro, alude a Ocampo mediante el humor, cuando ante la pregunta acerca de a quiénes metería en la cárcel, el poeta responde: 
A Leonardo Castellani y a Ernesto Sábato, para que se dejen de andar perdiendo el tiempo y puedan disponer de la serenidad indispensable para darnos los grandes libros que nos deben. Siempre, claro está, que la directora de la cárcel fuera Victoria Ocampo. (S/A 1960:9)

En esta pequeña humorada se complementa con una versión ya conocida, y apenas variada, de Ocampo como mecenas, al modo de un despotismo maternal. Es interesante pensar que tanto Clara Beter como Ocampo, en la entrevista, marcan una carencia: los escritores de izquierda no tienen (en rigor de verdad, habría que decir que no reconocen) pares femeninos. Beter fue un producto de la imaginación masculina ${ }^{5}$ y Ocampo era verdadera, efectivamente fue mecenas de muchos escritores pero nada más lejano de ella que la izquierda... Puede decirse que Beter representa el ideal femenino que no encuentra materialidad alguna en las mentes de los hombres y Ocampo, la despótica madre que nunca los cobijará.

Por último, la burguesa. En El escarabajo de oro, en 1962, Castillo y Liberman le dedican una editorial, "El lado de los huesos" (Castillo- Liberman 1960:2), al posicionamiento que tiene la revista en el campo cultural. El tono es bien confrontativo, especialmente con la revista Sur, de quien se quieren diferenciar para construir una identidad alternativa. Los autores celebran que El escarabajo de oro haya dejado de ser la voz de quienes escriben para ser representativa de los "hombres jóvenes" que viven la crisis cultural del presente.

\footnotetext{
${ }^{5}$ César Tiempo publicó poemas con el nombre de Clara Beter, una poeta - prostituta que enviaba sus versos a la revista Claridad. Empezó como una broma y terminó en un conflicto ya que Elías Castelnuovo creyó realmente existía la poeta y se generó toda una fábula respecto de ella que pasó a ser un mito que les servía a los jóvenes de Claridad para contraponerla a las despreciadas y ridiculizadas poetisas de aquella época.

Revista Zona Franca- Centro de estudios interdisciplinario sobre las mujeres (CEIM)- Maestría poder y sociedad desde la problemática de género (MG), Rosario, Argentina. ISSN, 2545-6504 http://zonafranca.unr.edu.ar/index.php/ZonaFrancal Numero 26 (2018). 
La hipótesis central es que ellos tienen un lugar en el campo intelectual y, desde allí, atacan a Sur, que representaría lo "vetusto" y "de derecha" ya que, dicen ellos, elevan tibiamente ideales humanistas que esconden la defensa de los privilegios de la burguesía. Así, dicen que Sur, revista que durante tantos años "protagonizó la avanzada literaria del país", hoy no es más que la "lengua muerta de nuestra cultura". Se refieren al posicionamiento anticastrista y al escándalo sucedido a raíz de la expulsión de José Bianco. Si bien aclaran que, cuando cerró El grillo de papel, Ocampo les escribió una carta de consideración, y que tienen entre sus colaboradores a escritores que están en la vereda de enfrente como Ezequiel Martínez Estrada y María Rosa Oliver; esto no justifica que ella declame "una amplitud humanista que nunca tuvo". Dicen que el humanismo tiene un poder combativo que nada tiene que ver con "las frases redactadas en una Villa de Mar del Plata", y se oponen a considerar que la literatura sea pura jocosidad, un juego que puede dar un resultado genial como el de Jorge Luis Borges pero que también

engendra con bastante más frecuencia señoras que palmotean, cenas en el Rotary, conferencias de Lin Yutang, o algarrobos parlantes. Estamos, nos parece, en condiciones de recuperar, para nosotros, no sólo lo más auténtico de la tradición literaria, sino el derecho a construir, por prepotencia de vida, esa tradición. (Castillo- Liberman 1960:2)

A la toma de posición y la dicotomía juventud /izquierda y vejez/derecha, subyace una imagen que fusiona cuestiones de clase y de género; y se sintetiza en la señora burguesa que representaría Ocampo. Así, a las viejas aduladoras se les oponen los hombres jóvenes. En verdad, esto resucita los prejuicios sexistas 
que prevalecían ante las poetisas de los años veinte. Pero, en la cita aparece otro elemento más, el "algarrobo parlante", que alude a una obra contemporánea de Ocampo titulada Habla el algarrobo y publicada en 1959. En esta, la autora cuenta, a través del árbol, la historia de la quinta Pueyrredón, que fue testigo de la llegada de Juan de Garay allá por 1580, escuchó hablar a José de San Martín, a Mariquita Sánchez de Thompson, a José Hernández y hasta llegó a conocer a Roque Sáenz Peña en 1900. Pero no sólo ello sino que en la contratapa aclara que no sólo una quinta histórica sino que es el lugar donde ella pasó gran parte de su infancia. Es decir que la obra abarca la historia familiar que es la historia nacional, que, a su vez, conforma la genealogía de la oligarquía porteña. Esta es la tradición de clase aludida y feminizada tras el "algarrobo parlante" y de la que Castillo y Libermann se quieren separar para construir una tradición crítica y propia.

Ante la idea instalada ya en la crítica respecto de la decadencia de la revista Sur en los años sesenta (y que la generación de Castillo instaló, como se puede leer en la editorial antes citada), Podlubne sostiene que, al contrario, la revista atrae a otros escritores, "jóvenes de diversas procedencias que coincidieron en la redacción de Sur entre otros lugares." (2012:7) Se refiere así a nombres como los de Alejandra Pizarnik o Sylvia Molloy. Es más, la revista se conformó como un espacio que daba lugar al disenso, al debate y a la disidencia sexual. Si consideramos esto último, Sur era más permeable a la visibilización de la homosexualidad y del feminismo que las revistas de izquierda, como la que estamos analizando. Esto a su vez proviene de "lo que Escari designa como los 
prejuicios de la izquierda intelectual reinante en esos años" (Podlubne 2012: 9) y que en definitiva permite explicar la difícil relación entre el feminismo, la disidencia sexual y la izquierda al interior del campo intelectual. Justamente, la editorial antes mencionada hace hincapié en la antinomia entre la revista Sur y las revistas culturales de izquierda y, en esta línea, la intención de Castillo es el de demonizar a Sur, para ubicarse ellos a la vanguardia de la literatura argentina. Sin embargo, siguiendo la pista de las continuidades que ve Podlubne (2014) entre Sur y Contorno, este gesto también está hablando de ciertos vínculos y continuidades entre los integrantes de ambas revistas, me refiero no sólo a Victoria Ocampo sino también a Ezequiel Martínez Estrada, Ernesto Sábato y María Rosa Oliver; quienes de distinto modo pero aparecen tanto en las páginas de una como de otra revista.

\section{Un feminismo apenas sugerido: Simone de Beauvoir y María Rosa Oliver}

Una figura habitual en la revista es la de Simone de Beauvoir que, junto con Jean Paul Sartre, conformaron el modelo ideal de pareja intelectual de aquellos años. En el número 6 de El grillo de papel, se publican dos artículos que tienen a ella como protagonista. Uno titulado "Simone de Beauvoir y Sartre en Cuba" que es una crónica del viaje que hacen ambos a Cuba, a pocos meses del triunfo de la revolución. Y el otro titulado como "Reportaje a Simone de Beauvoir". Ambos carecen de firma y provienen de la agencia de noticias Prensa Latina.

En el primero, el cronista narra el viaje desde el avión hasta diferentes escenas de la estadía, se detiene en retratos de los protagonistas, descripciones de los lugares, del tiempo, etc. En el relato, se mezclan las valoraciones del 
cronista con las transcripciones de las opiniones de la pareja sobre diversos temas. El estilo del cronista deja ver un matiz de sexismo al aportar frases que señalan diferencias de género estereotipadas en la caracterización de la pareja. Por ejemplo, comienza diciendo "Simone de Beauvoir quiere mantenerse en un segundo plano. Habla menos. (...) él, rigor, precisión, análisis; ella observando colores, formas, cosas." (S/A 1960: 4) Básicamente, él habla y ella observa. Esta esterotipia simple de género no se condice con la de la entrevista a la filósofa en la que es ella la que porta los valores en esta crónica considerados masculinos. Casi al final de la nota, el periodista le da cabida a la voz de la filósofa cuando ellos hablan con otra mujer, Haydée Santamaría, sobre el rol de las mujeres revolucionarias. En la charla con Santamaría, De Beauvoir le pregunta la razón de algo que afirma como un hecho: que las mujeres que se destacaron en la lucha, puntualmente: Haydée Santamaría, Celia Sánchez y Vilma Espín, no aceptaron "responsabilidad de envergadura" en el gobierno revolucionario. La filósofa lee en este hecho un retroceso hacia la subordinación de la mujer. Santamaría, dice el cronista, le responde que ellas "no se sentían capacitadas y que continúan en la tarea revolucionaria, a través de los compañeros. Haydée le dice que es tan importante tener madres como buenos funcionarios" (S/A 1960: 5) De Beauvoir le dice que ambas tareas no son irreconciliables y que le preocupa enormemente lo que dice porque cuando mujeres que han participado en roles tradicionalmente masculinos, los abandonan, hace que el resto de las mujeres queden oprimidas.

Como puede leerse, en este diálogo surge la defensa y la crítica hacia el rol tradicional de la mujer doméstica. Justamente, De Beauvoir cuestiona estos 
supuestos dejando ver las funestas consecuencias que esta situación acarrea para las mujeres, ya que mientras se habla de una sociedad más justa, se reproduce la opresión de género. El argumento patriarcal de Santamaría no es novedoso sino que parece tomado de las ideas vigentes luego de la Segunda Guerra Mundial, por las que se intenta que las mujeres vuelvan al hogar, es decir, a sus roles establecidos de subordinación al hombre para colaborar con el restablecimiento de la sociedad. Y el argumento de De Beauvoir es "renovador", revolucionario podríamos decir, y se sustenta en las ideas que ya había expresado en El segundo sexo, en 1949.

Esta crónica fue extraída de la agencia de noticias de Cuba, Prensa Latina, sin firma y fue publicada en El grillo de papel en octubre/ noviembre de 1960, es decir cuando aún no hacía dos años que se había establecido el gobierno revolucionario. Otra versión de esta misma crónica fue publicada por la revista cubana Revolución, en febrero de 1960 y esta vez con la firma de unos de los principales periodistas de la agencia: Lisandro Otero. Esta versión es un poco más extensa y precisa en algunos detalles. Por ejemplo, Otero asume la autoría de la crónica pero aclara que quien acompañada a la pareja y hacía las preguntas era Carlos Franqui. Las citas que analizamos anteriormente son idénticas, incluso, tampoco aparece en cita directa la palabra de Santamaría sino que es parafraseada por el cronista.

Es importante tener en cuenta que ese mes en que la pareja francesa se quedó en Cuba ha sido central para la conformación de la imagen de la Revolución cubana hacia el resto del mundo. Por eso, es llamativo el contraste 
entre lo que dice la crónica y lo que sucede en los hechos. Tanto Haydée Santamaría como Celia Sanchez y Vilma Espín sí ocuparon cargos importantes dentro del gobierno: Santamaría fundó y dirigió La casa de las Américas, Espín se ocupó de organizar la Federación de Mujeres Cubanas y Sánchez fue secretaria de la Presidencia del Consejo de Ministros de Cuba. ¿Estarían midiendo el impacto que ambos argumentos podían tener en el exterior? ¿considerarían que las demandas del feminismo formaban parte de ideas de la burguesía? ¿creerían que la desigualdad de género se resolvería como una consecuencia de la asimilación de la revolución?

La entrevista que se le hace a De Beauvoir, también fue levantada de Prensa Latina y hace hincapié en su imagen de escritora: escribir le demanda entre 607 horas diarias de trabajo, cada novela supone para ella toda una investigación sobre la época y sobre los personajes. Además, confiesa que desde niña "quiso ser un autor célebre" (S/A 1960: 15) y el momento más feliz de su vida fue cuando se encontró Sartre, ya que, según sus palabras, fue su maestro y también alguien con quien podía discutir de igual a igual los asuntos que les preocupaban. Se piensa a sí misma como una mujer que no sufrió discriminación alguna aunque sí es capaz de reconocer la subordinación que sufren otras mujeres y ese fue el motor que la llevo a escribir El segundo sexo, libro en el que plantea interrogantes que se desprenden del problema femenino. ${ }^{6}$ Esta autofiguración como mujer

6 "R.:- En 1947 quise escribir un libro sobre mis experiencias personales. En los medios intelectuales que frecuentaba, jamás encontré discriminación respecto a mi sexo. Pero al mirar a mí alrededor me di cuenta de que el problema femenino estaba lejos de ser resuelto. Traté de profundizar esa cuestión en El segundo sexo, al que los críticos han tachado de ser una obra de 
independiente y profesional que no vivió situaciones de discriminación coincide con la imagen de la escritora y de la militante de esos años. Nari (2002) comenta que muchas mujeres ligadas al campo intelectual o a la militancia política se describían a sí mismas como mujeres profesionales, comprometidas con la realidad política y con la profesión, se esforzaban por afirmarse como iguales a los hombres y la percepción de la opresión de la mujer estaba más enfocada hacia afuera, hacia otras mujeres a las que había que ayudar en todo caso. Liliana Heker, sin ir más lejos, se coloca en este lugar pero con la diferencia de que niega enfáticamente que exista desigualdad entre el hombre y la mujer. ${ }^{7}$

Como se dijo antes, en el campo cultural argentino, ambos filósofos fueron referentes del pensamiento de izquierda, aunque la faceta feminista de De Beauvoir tuvo un lugar bastante secundario. Es decir, la presencia de la filósofa en la revista estaba dada más por la recepción y lectura de sus novelas e incluso por ella misma como personaje, quedando en un segundo plano El segundo sexo, el que fue leído pero con reparos. Según Nari (2002), el libro fue leído entre las mujeres intelectuales y generó lecturas fascinadas o furiosas pero que permanecieron en la experiencia individual, en la conversación privada, sin llegar al debate público. Beauvoir, además, fue traducida por Silvina Bullrich quien

resentimiento. Sin embargo, no es más que el sereno interrogante de una mujer ante los problemas femeninos. Estos dos volúmenes han sido criticados por los hombres, las mujeres, por el contrario, en general los han apreciado." (15)

${ }^{7}$ En un reportaje que le hacen en 1965, cuando se le pregunta si es feminista dice "¿A qué mujer se le ocurre reivindicar en bloque a las otras mujeres? ¿Te animarías a, vos, a defender a todos los hombres", luego sobrevalora la obra de Otto Weininger y considera que, en cambio, la condición de judía y de proletaria sí merecen ser tenidas en cuenta ya que son marcas de la injusticia social. (Vázquez Santamaría 1965:22)

Revista Zona Franca- Centro de estudios interdisciplinario sobre las mujeres (CEIM)- Maestría poder y sociedad desde la problemática de género (MG), Rosario, Argentina. ISSN, 2545-6504 http://zonafranca.unr.edu.ar/index.php/ZonaFranca| Numero 26 (2018). 
además adscribe a sus ideas; y algunos de sus ensayos fueron publicados en Sur, a pesar de la distancia ideológica que tenía con la revista. María Rosa Oliver conoce el libro e incluso en 1947 traduce un artículo llamado "Literatura y metafísica" para un número especial de Sur dedicado a Francia. Oliver, colaboradora en Sur y amiga íntima de Ocampo se pasa a las filas del comunismo, colabora activamente en la Guerra Civil Española y en la revista de Castillo, en 1963, la entrevistan con motivo de su actuación en el Congreso por el desarme. Las preguntas que le hacen rondan sobre la relación entre la literatura, la juventud, los escritores soviéticos y el pacifismo. En un momento, el entrevistador le pregunta si cree que la mujer está en un plano de igualdad respecto del hombre en cuanto a la creación artística entre otras cosas y Oliver contesta parafraseando la biografía de la hermana de Shakespeare, imaginada por Virginia Woolf; y justifica señalando la escasez de escritoras clásicas en lengua española. Entonces, el entrevistador le sugiere si en verdad no serán los prejuicios sobre la mujer los que impiden que ésta sea intelectual y ella responde que "los prejuicios, los tabús, se inventan para justificar lo injusto" (S/A 1963:10) ya que en cuanto la mujer se independiza económicamente, los deja de lado y lo sostiene mencionando a Beauvoir en El segundo sexo.

Luego, el entrevistador le pregunta por qué la mujer no se destaca en la ciencia o en la literatura pero sí iguala o supera al hombre en teatro o danza. La pregunta reproduce un prejuicio extendido en el imaginario socio- sexual de la época que suponía que la mujer se destacada en actividades que comprometían su cuerpo o su subjetividad y que no podía realizar actividades relacionadas con el 
razonamiento o la abstracción. Es más, quien le dio un status seudo -filosófico fue

Ernesto Sábato, quien en esos años tenía cierto prestigio y en la revista lo entrevistaban y lo seguían bastante. Sábato pocos años antes había protagonizado una polémica con Ocampo, sobre la misoginia a raíz de su libro de ensayo, Heterodoxia (1953), en el que dedicó varias páginas a afirmar la diferencia sexual basada en la inferioridad biológica de la mujer, tomando como argumento lo antedicho. ${ }^{8}$ Oliver, en cambio, no se detiene en discutir con el periodista sino que prefiere apelar al humor al decirle: "Me parece que este muchacho tiene prejuicios...". (S/A 1963:12)

\section{Escritoras convencionales}

El imaginario socio- sexual que se despliega en las revistas al aparecer la mujer deja hablar al androcentrismo por el que se afirma una división sexual de los espacios de expansión de la subjetividad por la que las cuestiones relativas a las

${ }^{8}$ Con respecto a este argumento, dice Sábato: "No son causas históricas, pues, las que hacen que la mujer no figure con más frecuencia en la historia de las creaciones. Aunque influyan, no son la causa decisiva y profunda. Al fin de cuentas nadie prohibió nunca a la mujer la especulación filosófica, ni la música, ni el dibujo. Es que por debajo de las formas históricas hay radicales condiciones biológicas y metafísicas que apartan a la mujer de la creación y del descubrimiento. Y si produce en el arte o en la ciencia, es en aquellos órdenes que están enlazados a su esencia profunda, a su cuerpo, a su subjetividad: la danza, la interpretación teatral, la interpretación musical, la novela de pasiones (sobre todo autobiográficas), las memorias, los diarios; todo aquello que tiende a la imitación, la representación y la conservación." (56) En varias ocasiones, Sábato es mencionado, en la revista, como una persona de quien se valoran sus opiniones en relación al rol de los escritores en el contexto político latinoamericano, hasta, podría decirse que estiman, incluso, su misoginia ya que en el número 5 de El escarabajo de oro rodeado de dibujos que hacen humor con la animalización de la mujer (en un caso, un hombre que se dirige amorosamente a una mujer que parece una vaca y en el otro, un hombre mata a una mujer con un insecticida) aparece una cita de Heterodoxia que dice que la mayor virtud de la mujer es el altruismo y por eso su mayor defecto es el egoísmo ya que "su mundo es concreto y pequeño" al contrario del hombre que cuando se equivoca hace "una guerra mundial o un sistema filosófico". (13)

Revista Zona Franca- Centro de estudios interdisciplinario sobre las mujeres (CEIM)- Maestría poder y sociedad desde la problemática de género (MG), Rosario, Argentina. ISSN, 2545-6504 http://zonafranca.unr.edu.ar/index.php/ZonaFranca| Numero 26 (2018). 
emociones, al amor y a las relaciones intergenéricas son propias de la identidad femenina; mientas aquellas relativas a la vida política y a la cultura se recortan como propias de una identidad masculina. En el imaginario de la revista, la feminidad queda reducida a las emociones y a las ideas burguesas, cuando no es descalificada de plano por superficial o poco seria; y este prejuicio es que el que permite comprender por un lado, la vigencia que cobra Clara Beter que retorna como una alegoría de la inexistencia de la escritora de izquierda. Por otro, permite comprender la razón por la que escritoras como Guido o Heker rechazan el reflejo de Madame Bovary que les devuelve el espejo y prefieren plegarse a los valores masculinos jerarquizados. Mientras tanto, la reflexión feminista estaba marcada por dos textos que anteceden a la teoría feminista (Un cuarto propio de Virginia Woolf y El segundo sexo de Simone de Beauvoir); pero casi no hay recuerdo de la historia del feminismo nacional y menos aún, de las posturas de las escritoras al respecto. 


\section{Bibliografía}

BATTICUORE, Graciela (2005). La mujer romántica. Lectoras, autoras y escritores en la Argentina romántica. 1830 y 1870, Buenos Aires: Edhasa.

BLANCO, Mariela (2006). "Cortázar- Viñas: afirmación y negación de una polémica". Texturas, 11-17.

CALABRESE, Elisa 2005. "Las revistas de Abelardo Castillo. Un proyecto cultural alternativo". CELEHIS. Revista del centro de letras hispanoamericanas, año 14/15, nro. 17: 39-57.

CALABRESE, Elisa (2006). Animales fabulosos. Las revistas de Abelardo Castillo, Mar del Plata: Editorial Martín.

CASTILLO, Abelardo- Liberman, Arnoldo 1960. "La ley de las vísceras". El grillo de papel, año 2, nro. 5, agosto- septiembre, 2.

CASTILLO, Abelardo- Liberman, Arnoldo 1962. "El lado de los huesos". Revista El escarabajo de oro, año 3, nro.6, abril, 1.

CATELLI, Nora (2001). Testimonios tangibles. Pasión y extinción de la lectura en la narrativa moderna. Barcelona: Anagrama.

COSSE, Isabella (2010). Pareja, sexualidad y familia en los sesenta. Buenos Aires.: FCE.

S/A 1963 "Los mingitorios de la literatura". Revista El escarabajo de oro, año 4, nro. 16, enero, 4.

FERRERO, Adrián (2007) "Exilio poético y exilio político: la polémica entre Liliana Heker y Julio Cortázar en la revista cultural El ornitorrinco". Questión. Revista especializada en periodismo y comunicación, nro. 16. La Plata: UNLP.

FIRPO, Norberto (1961). "Bicherías. Como encarar una novela de amor". Revista El escarabajo de oro, año 1, nro. 1, mayo/ junio, 14-15.

GRANDE COBIÁN, Leonardo (2006). “¿Un bicho raro? El programa político de El Grillo de Papel y El Escarabajo de Oro, 1959-1964". Razón y Revolución, oㅜ 15, Buenos Aires: 11-29. 
HEKER, Liliana 1967. "Las hermanas de Shakespeare. Sobre las mujeres y la literatura" 1era parte. Revista El escarabajo de oro, año 8, nro. 34, Julio- agosto, 10-12, 14.

HEKER, Liliana (1967). "Las hermanas de Shakespeare. Sobre las mujeres y la literatura" 2 da parte. Revista El escarabajo de oro, año 8, nro. 35, noviembre, 15 y 18.

HUYSEEN, Andreas (2002). Después de la gran división. Modernismo, cultura de masas, posmodernismo. Bs. As.: Adriana Hidalgo editora.

KRISTEVA, Julia (1998). Poderes de la perversión. Buenos Aires: Catálogos.

LITTAU, Karen (2008). Teorías de la lectura: libros, cuerpos y bibliomanía. Barcelona: Manantial.

NARI, Marcela (2002). "No se nace feminista, se llega a serlo. Lecturas y recuerdos de Simone de Beauvoir en Argentina, 1959-1990". Revista Mora nro. 8, UBA: 59-72.

PODLUBNE, Judith (2012). "Sur en los 60. Hacia una nueva sensibilidad crítica". Revista Badebec, nro. 2: 44-60.

PODLUBNE, Judith (2014). "Un arte para el hombre. Literatura y compromiso en Sur y Contorno". Revista Anclajes, XVIII : 49-66.

S/A (1963). "María Rosa Oliver. Reportaje al pie del congreso". El escarabajo de oro, año 3, nro. 16, enero, 10-12.

S/A (1960). "Simone de Beauvoir (reportaje)". El grillo de papel, año 2, nro. 6 , octubre -noviembre, 15.

S/A (1960). "Reportaje a César Tiempo". El grillo de papel, año 2, nro.6, octubre- noviembre, 9.

S/A (1960). "Simone de Beauvoir y Sartre en Cuba". El grillo de papel, año 2, nro. 6, octubre-noviembre, 4.

S/A (1962). "Sin título". Revista El escarabajo de oro, año 2, nro. 5, febrero, 13.

SÁBATO, Ernesto (1953). Heterodoxia, Buenos Aires: Emecé.

SAÍTTA, Sylvia (2015). "El grillo canta en continuado". Revista $\tilde{N}$, Buenos Aires, 16. 
VÁZQUEZ SANTAMARÍA, Jorge (1965). "Cazando grillos con Liliana Heker". Revista El escarabajo de oro, año 5, nro. 28, abril, 21-22.

VILLARREAL (1960). "El grillo y la lucha de clases". El grillo de papel, año 2, nro. 6, octubre-noviembre, 37. 